\title{
PLANT AS SOURCE OF PESTICIDES: CURRENT STATUS AND
}

\section{FUTURE PERSPECTIVE.}

\author{
S. R. Kochhar ${ }^{1}$ R. Urkude ${ }^{2}$ V. Dhurvey ${ }^{3}$ D. C. Sindhimeshram ${ }^{4}$ \\ 1Department of Chemistry, Nagpur Institute of Technology, Nagpur \\ ${ }^{2,4}$ Department of Chemistry Shivaji Science College,Congress Nagar, \\ Nagpur \\ ${ }^{3}$ Department of Zoology,RTM,Nagpur University , Nagpur.
}

\begin{abstract}
From centuries humans have been using natural insecticides to control insect pests. With advancement in technology, researchers observed the compounds responsible for activity in the natural products.As soon as nature of active constituent was known synthetic analogues were investigated in attempt to elucidate the principles governing their activity and that lead to synthesis of simple or more potent insecticides e.g pyrethrins responsible for insecticidal activity was extracted from chrysanthemum flowers, its structure was studied and modified to develop synthetic pyrethroids . These synthetic insecticides were found to have greater insecticidal activity ,photostability and requires lower dose rates than the conventional pesticides. The usefulness of synthetic pesticides in agricultural practices is unquestionable. However, injudicious use of synthetic pesticides present hazardous impacts on humans and environment but judicious use may help to control pest and environmental problems. This review covers the historical use of natural products in agricultural practices, the impact of natural products on the development of new pesticides and the future prospects for natural products-based pest management,with special focus on pyrethrins and the following synthetic pyrethroid insecticides.
\end{abstract}

\section{KEY WORDS}

Plant resources, Synthetic pesticides, Pyrethrins, Pyrethroids.

\section{Introduction}

Humanoids have been on earth for more than 3 million years, while insects have existed for at least 250 million years and no plot of land is immune to attack by insects. A huge loss of nearly a fifth of the produce is estimated to be due to pest attacks on standing crops and storage.Plants need chemical defenses, either natural or synthetic, in order to survive pest attack .Plant products have been successfully 
exploited as insecticides, insect repellents and antifeedants .Humans started using pesticides and insecticides well before 2000 years ago. The first form of pesticide was elemental sulphur dusting which was used by Sumerians around 4,500 years ago. Whilst about 3200 years ago the Chinese were using mercury and arsenical compounds for controlling body lice ${ }^{1}$. By 17 th century, nicotine sulphate was extracted from tobacco leaves and was used as insecticide.

Around 19th century, two more natural substances like pyrethrum which is derived from chrysanthemums and rotenone which is derived from the roots of tropical vegetables came into existence. Tar was also used on tree trunks to trap crawling insects. Weeds were controlled mainly by hand weeding but various chemical methods are also described such as the use of salt or sea water ${ }^{2,3}$.

Early use patterns showed that most pest control products were naturally occurring basic poisons. They were nonselective in nature, persistent and toxic to many forms of life. It was World War II that opened the Modern Era of Chemical control by introducing a new concept of insect control with synthetic organic insecticides.The growth in synthetic pesticides accelerated in the 1940s with the discovery of the effects of DDT, BHC, aldrin, dieldrin, endrin, chlordane, parathion and captan. These products were effective and inexpensive with DDT being the most popular, because of its broad-spectrum activity ${ }^{1,4}$.There are many classes of synthetic pesticides the main classes consist of organochlorines, organophosphates, carbamates, and pyrethroids. The pesticide industry has favored synthetic pesticides over natural toxins for several reasons like the physicochemical properties of the natural pestactive compounds are often unsuitable for use as a pesticide, natural toxins are often too structurally complex (e.g., multiple stereogenic centers) to be economical pesticides and there is limited supply of natural pesticides. 
When scarcity of natural substances necessitates, chemical synthesis is viable alternative. This article will explain the origin of synthetic pyrethroids from natural pyrethrins.

\section{Structures and insecticidal properties of pyrethroids}

Pyrethroid insecticides have evolved in a classical sequence.Activity of pyrethrins was observed in natural extract and the compounds responsible were isolated and identified and active analogues were synthesized 5 .

Pyrethrins are a combination of six natural chemicals extracted from the commercial flowers Chrysanthemum cinerariaefolium and Chrysanthemum cineum 6, 7. The flowers of the plant are harvested shortly after blooming and are either dried and powdered or the oils within the flowers are extracted with solvents. The resulting pyrethrin containing dusts and extracts usually have an active ingredient content of about $30 \%$. These active insecticidal components are collectively known as pyrethrins. The six biologically active chemicals in pyrethrins are responsible for the knockdown properties of the insecticide ${ }^{8}$ (Fig 1). Two pyrethrins are most prominent, pyrethrin-I and pyrethrin-II. The pyrethrins have another four different active ingredients, Cinerin I and II and Jasmolin I and II. Pyrethrin I, cinerin I, and jasmolin I are esters of chrysanthemic acid where as pyrethrin II, cinerin II, and jasmolin II are esters of pyrethric acid. Chrysanthemic acid and pyrethric acid combine with one of three alcohols (pyrethrolone, cinerolone, and jasmololone) to form the respective six active ingredients 9. After elucidation of the chemical structures of the six terpenoid esters (pyrethrins) responsible for the insecticidal activity of these plants, many synthetic analogs have been patented and marketed (Fig 2 \&3). There are two types of pyrethroid that differ in chemical structure and symptoms of exposure. Type I pyrethroids include allethrin, tetramethrin, resmethrin, dphenothrin, bioresmethrin, and permethrin and Type II pyrethroids 
include, cypermethrin, cyfluthrin, deltamethrin, cyphenothrin, fenvalerate, and fluvalinate. ${ }^{10,11}$ Although the early stages of this process made reference to the natural pyrethrins as templates subsequent stages employed newly discovered synthetic pyrethroids with desirable insecticidal activity, stability, and other properties as the templates for the further design of new compounds (Fig 4). Example- Inclusion of a cyano substituent in the 3-phenoxybenzyl alcohol moiety, produced deltamethrin, a compounds with greater insecticidal potency . Deltamethrin (Fig. 5) was developed in 1974 and was the first pyrethroid containing the alphacyano- 3-phenoxybenzyl moiety ${ }^{12}$. Decades of research and development by the agrochemical industry and by government and academic research laboratories have resulted in a wide range of pyrethroid structures and a multitude of uses in agricultural, veterinary, medical and household pest control. The development of synthetic pyrethroid insecticides has involved an iterative process of structural modification and biological evaluation. The new chemical class of pyrethroids was given phenomenal support by the agricultural community due to the very high activity, low use rates, broad spectrum of activity, excellent mammalian safety profile, cost-effectiveness, and was quickly accepted by the market 13

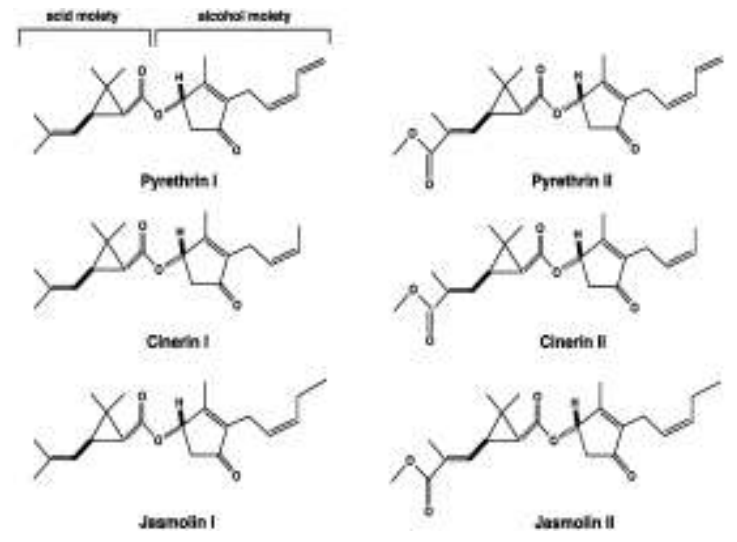

Fig 1) structure of six natural pyrethrins 


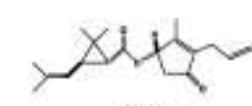

avenen

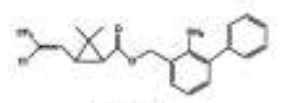

wasetson<smiles>CC(C)CC1C(C)C1CC(C)(C)C1CCCC(CC2CCCCC2)C1</smiles>

Detronem

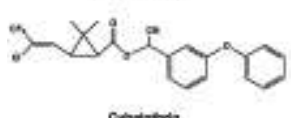

opustorn
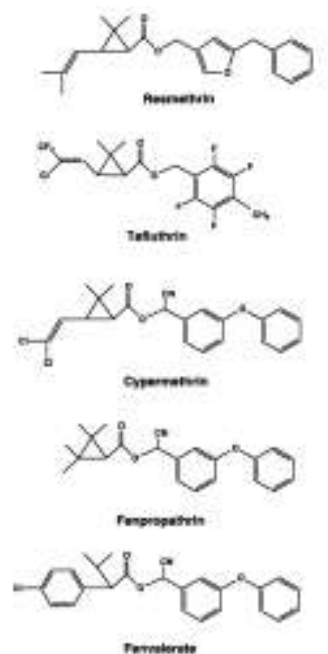
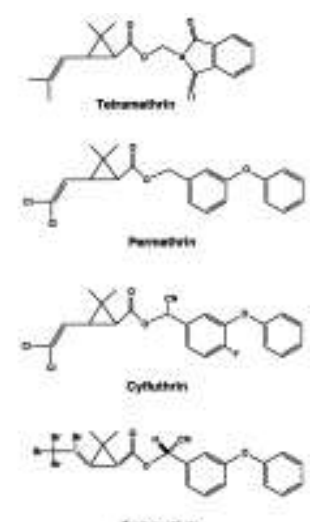

(Fig2) Structures of synthetic pyrethroid

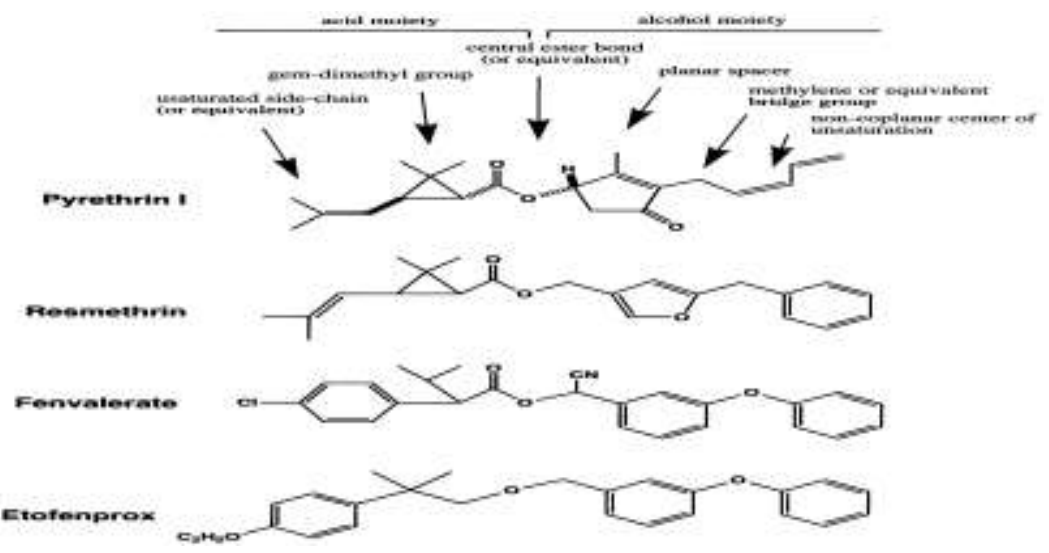

(Fig 3) Important features of pyrethroid structure-activity relationships illustrated by pyrethrin I and three synthetic pyrethroids. 


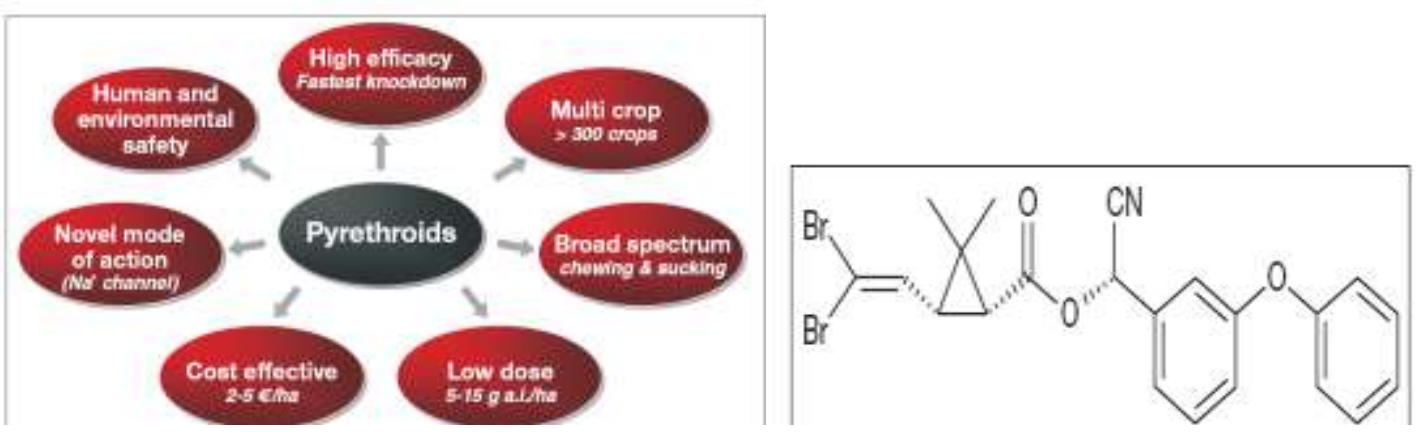

Fig 4

Fig. 5: Molecular structure of deltamethrin

Botanicals include crude extracts and isolated or purified compounds from various plants species and commercial products .Quantitatively, the most important botanical is pyrethrum, followed by neem, rotenone and essential oils that are typical used as insecticides include pyrethrum, rotenone, rape seed oil, quassia extract, neem oil, nicotine.Plants are capable of synthesizing an overwhelming variety of small organic molecules called secondary metabolites, usually with very complex and unique carbon skeletonructures ${ }^{14}$.

\section{Conclusion}

Plants contain a virtually untapped reservoir of pesticides that can be used directly or as templates for synthetic pesticides. Numerous factors have increased the interest of the pesticide industry and the pesticide market as natural products as pesticides has limited environmental stability and low activity compared to synthetic pesticides. Pesticide chemistry has allowed better resistance management and improved selectivity.Researches should be carried out to develop safer molecules which could undergo photodegradation, microbial degradation as well as chemical degradation leaving very less amount of residues in the environment,having low mammalian toxicity,less soluble in water,leaching potential shall be less or absent and the molecular weight of new molecules shall be in the range from 200-450. Synthetic 
pesticides present hazardous impacts on humans and environment but many of the harmful effects from applying chemical pesticides are observed not so much from pesticide use but from pesticide misuse. This includes over application, repeated application of the same pesticide, poor application technology however to overcome this judicious use may help to minimize pest and environmental hazards.

\section{REFERENES}

The History of Pesticides, Organic Pesticides, (2008). http://blog.ecosmart.com/index.php/2008/09/19/the-history-ofpesticides/

J. Janek. History of Horticulture, Roman Agricultural History;, Purdue University http://www.hort.purdue.edu/newcrop/Hort_306/text/lec18.pdf

A.E. Smith and D.M. Secoy, J. Ag. (1975), Forerunners of Pesticides in Classical Greece and Rome; Food Chem, 23 :6, pp 1050 http://www.hort.purdue.edu/newcrop/history/lecture18/r_18$\underline{1 . h t m l}$

K.S. Delaplane (2000), Pesticide Usage in the United States: History, Benefits, Risks, and Trends; Bulletin 1121, Cooperative Extension Service, The University of Georgia College of Agricultural and Environmental Sciences http://pubs.caes.uga.edu/caespubs/pubs/PDF /B1121.pdf

H Staudinger and L Ruzicka; (1924), Helv. Chim.Acta, 7, pp 177-201 McLaughlin, G. A. (1973), History of pyrethrum. In "Pyrethrum; The Natural Insecticide”. J. E. Casida (eds.). Academic Press. New York, NY,pp 3

Todd, G. D., Wohlers, D., and Citra, M. (2003), Toxicology Profile for Pyrethrins and pyrethroids. Department of Health and Human 
Services. Agency for Toxic Substances and Disease Registry. Atlanta, GA.

Moorman, R., and Nguyen, K. (1997), Identification and quantitation of the six active compounds in a pyrethrin standard. J. Assoc. Off. Anal. Chem. 65, pp 921-926

Head, S. W. (1973) Composition of pyrethrum extract and analysis of pyrethrins. In "Pyrethrum; The Natural Insecticide". J. E. Cadisa (eds.). Academic Press. New York, NY., pp 25-49

Klaassen, C. D., Amdur, M. O., and Doull, J. (Eds.). (1996). Casarett \& Doull's Toxicology. The Basic Science of Poisons (5 ed.). Toronto: McGraw-Hill Companies, Inc.

Ray, D. E (1991), Pesticides derived from plants and other organisms. In W. J. Hayes, Jr. \& E. R. Laws (Eds.), Handbook of Pesticide Toxicology. Vol. 2. Toronto: Academic Press pp 585-593

Elliott, M., Farnham, A. W., Janes, N. F., Needham, P. H., and Pulman, D. A. (1974), Synthetic insecticide with a new order of activity Nature 248, pp 710-711.

Watkinson, I. (1990), A Pyrethroids and the economics of pest management In: The Pyrethroids Insecticides: A Scientific Advantage for Human Welfare? pp 466

Sarker, S.D., Latif, Z., and Gray, A.I. (2005), Natural product isolation. Humana Methods in biotechnology, 20.Press, Totowa, New Jersey. pp 1-25 